\title{
Medium and long latency EMG responses in leg muscles: Parkinson's disease
}

\author{
E SCHOLZ, ${ }^{*}$ H C DIENER, ${ }^{*}$ J NOTH, $\dagger$ H FRIEDEMANN, $\dagger$ J DICHGANS, ${ }^{*}$ \\ M BACHER*
}

\begin{abstract}
From the Departments of Neurology, University of Tübingen* and Alfred Krupp Hospital in Essen, $\dagger$ Federal Repubic of Germany
\end{abstract}

SUMMARY Short, medium, and long latency EMG responses to muscle stretch from triceps surae and anterior tibialis muscles were recorded in normals and in 33 patients with Parkinson's disease. The latencies of all EMG responses except short latency were normal in patients with Parkinson's disease. The integrals of the medium latency responses in the stretched triceps surae muscle were significantly increased in patients. This result indicates a modulatory influence of the basal ganglia on medium latency EMG responses.

The description of altered medium and long latency EMG responses after muscle stretch and their correlation with clinical signs of Parkinson's disease has been the subject of several earlier studies. ${ }^{1-3}$ Most of the recent studies investigated arm, wrist or finger muscles. Responses of leg muscles have only been investigated in sitting or supine subjects. ${ }^{4-6}$ This study reports additional data on medium and long latency EMG responses of leg muscles while standing. The reasons for the extension of available data are as follows: firstly, these responses contribute to postural stabilisation ${ }^{7}$ and disturbances of upright posture are a predominant symptom in patients with Parkinson's disease. Secondly, these responses are different from those evoked in a sitting subject. ${ }^{8}$ Thirdly, it is difficult to separate clearly the end of the M2-response (nomenclature from reference 1) from the beginning of $\mathrm{M} 3$ in human wrist muscles, whereas in a standing subject the medium and long latency responses occur in antagonistic leg muscles after a sudden tilt of the supporting platform and therefore allow for a distinct analysis of the two components. ${ }^{78}$ From a functional point of view the long latency responses in the antagonist of the stretched leg muscle after a platform tilt toe-up or toe-down may be inter-

Address for reprint requests: Dr med E Scholz, Neurologische Universitätsklinik, Liebermeisterstr 18-20 D-7400 Tübingen, FRG.

Received 5 September 1984 and in final revised form 13 February 1986.

Accepted 15 February 1986 preted as an analogue of M3 in the stretched arm or wrist muscle, since in the first situation long latency reflexes stabilise the upright posture, whereas in the second case $M 3$ restores the initial position of the arm or hand after the externally applied disturbance. Our results indicate that Parkinson's disease modulates the amplitude of the medium latency response, but leaves the long latency response unchanged.

\section{Methods}

(A) EMG responses from leg muscles Subjects stood on a force measuring platform which could be tilted around an axis co-linear with the ankle joints. Patients were instructed to maintain an upright position. The platform was unexpectedly tilted $4^{\circ}$ toe-up with $50^{\circ} / \mathrm{s}$. EMGs were recorded by surface electrodes from the triceps surae and anterior tibialis muscles, fullwave rectified, filtered $(16-1000 \mathrm{~Hz})$, amplified and stored together with the data of platform position, centre of foot pressure, and head and hip angle on a tape recorder for further processing. Data of eight consecutive platform tilts with time intervals of 5-15s between single trials were averaged. By means of a computer program we measured latencies, durations, and integrals of the three EMG responses (fig 1). Background EMG activity measured during $100 \mathrm{~ms}$ prior to platform tilt ranged between 2 and $5 \%$ of the size of short latency. We decided to measure EMG integrals from raw EMG records because an earlier study revealed a much higher interindividual variation when we measured EMG integrals in relation to maximal voluntary level of EMG.

(B) The clinical evaluation of patients concerning rigidity and akinesia was performed separately by using a rating scale ranging from absent (I), slight (II), moderate (III) to severe (IV) for each extremity. 


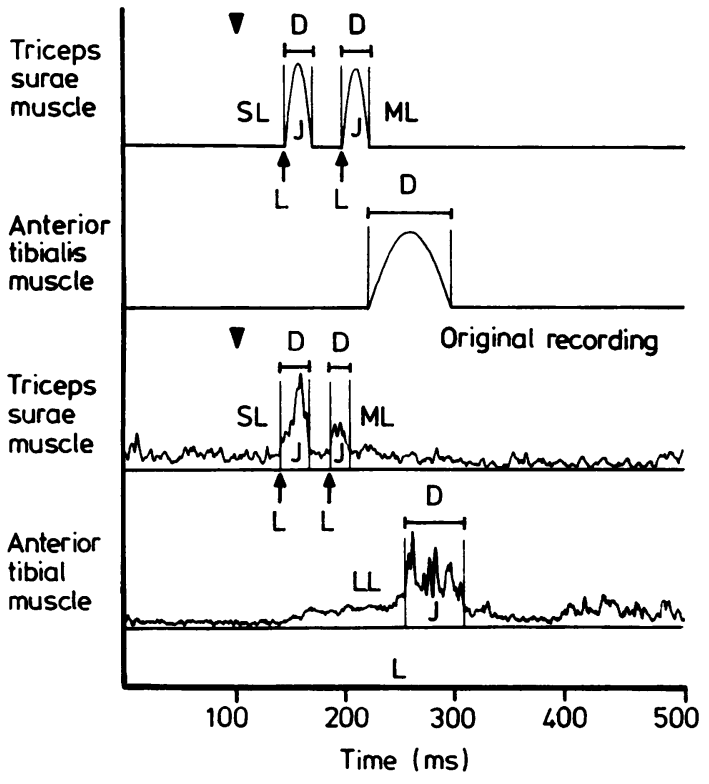

Fig 1 Upper part: schematic drawing of rectified EMG responses after platform tilt toe-up. Means of latencies and integrals from 30 normals, short latency response (SL) and medium latency response ( $M L$ ) in triceps surae (first line) and long latency response $(L L)$ in anterior tibialis muscle. Lower part: original EMG recording, platform tilt toe-up indicated by black arrow, normalised EMG amplitude. $L=$ latency (ms), $I=$ integral (arbitrary units), $D=$ duration $(m s)$.

\section{Patients}

EMG responses from leg muscles were examined in 33 patients with Parkinson's disease. According to the Hoehn and Yahr scale ${ }^{9}$ six patients were rated stage II, nineteen stage III, and eight stage IV. The mean age was 66.7 years
( $\mathrm{SD}=9 \cdot 5$ years, range 41 to 80 years). During the early experiments EMG electrodes were placed only unilaterally, later we recorded from both legs. Fifty six recordings from antagonistic pairs of leg muscles were thus available from the 33 patients. Data from the patients were compared with an age matched control group $(n=20$, mean age 59.3 years, $\mathrm{SD}=7 \cdot 7$ years, range 47 to 74 years).

\section{Results}

\section{EMG responses from leg muscles}

A platform tilt toe-up evoked a stretch reflex in the triceps surae with a mean latency of $44.5 \mathrm{~ms}$ in normals and a medium latency response in the same muscle at $82.7 \mathrm{~ms}$. Figure 1 shows a recording from a healthy subject (lower part) and the calculated mean values from 30 normals (upper part). Short latency responses were absent in two normals and 11 patients with Parkinson's disease, mostly due to an additional, age-related polyneuropathy. The short latency was significantly increased in the patients, possibly due to the same mechanism. Medium latency responses were missing in three legs of normals and in four legs of patients. Short latency and medium latency responses both functionally destabilise upright posture, since by their action they enforce the passive backward motion of the body. The long latency response occurring at about $130 \mathrm{~ms}$ in normals and patients stabilises upright posture. The mean latencies of medium latency and long latency EMG responses from both the triceps surae and the anterior tibialis muscles showed no difference between patients with Parkinson's disease and normals (see table). Durations and integrals of the rectified and normalised medium latency responses, however, were increased in patients with Parkinson's disease. Figure 2 gives examples of the normal or missing short latency response but increased duration and integral of medium latency responses in two different patients with Parkinson's disease.

Table EMG responses in triceps surae ( $S L, M L)$ and anterior tibialis muscle $(L L) .40$ recordings from normals $(n=20)$, 56 recordings from patients $(n=33)$

\begin{tabular}{|c|c|c|c|c|c|c|}
\hline & \multicolumn{3}{|c|}{ Normals } & \multicolumn{3}{|c|}{ Parkinson } \\
\hline & $A M$ & $S D$ & $\bar{n}$ & $A M$ & $S D$ & $n$ \\
\hline \multirow{3}{*}{$\begin{array}{l}\text { Mean latencies (ms) } \\
\text { SL } \\
\text { ML } \\
\text { LL } \\
\text { Mean duration (ms) } \\
\text { SL } \\
\text { ML } \\
\text { LL } \\
\text { Integral (arbitrary units) } \\
\text { SL } \\
\text { ML } \\
\text { LL }\end{array}$} & $\begin{array}{r}44.5 \\
82.7 \\
131.1\end{array}$ & $\begin{array}{r}5.0 \\
9.6 \\
20.5\end{array}$ & $\begin{array}{l}38 \\
37 \\
40\end{array}$ & $\begin{array}{r}47.5^{+} \\
89.2 \\
138.5\end{array}$ & $\begin{array}{r}6 \cdot 7 \\
23.9 \\
22 \cdot 1\end{array}$ & $\begin{array}{l}45 \\
52 \\
56\end{array}$ \\
\hline & $\begin{array}{l}24 \cdot 3 \\
28 \cdot 7 \\
77 \cdot 7\end{array}$ & $\begin{array}{r}6 \cdot 0 \\
10 \cdot 9 \\
17 \cdot 9\end{array}$ & $\begin{array}{l}38 \\
37 \\
40\end{array}$ & $\begin{array}{l}23.5 \\
42.5^{+} \\
85 \cdot 2\end{array}$ & $\begin{array}{r}6 \cdot 2 \\
14.9 \\
28.2\end{array}$ & $\begin{array}{l}45 \\
52 \\
56\end{array}$ \\
\hline & $\begin{array}{l}11 \cdot 9 \\
14 \cdot 3 \\
37 \cdot 4\end{array}$ & $\begin{array}{r}5 \cdot 3 \\
7 \cdot 3 \\
10 \cdot 3\end{array}$ & $\begin{array}{l}38 \\
37 \\
40\end{array}$ & $\begin{array}{l}8 \cdot 4^{+} \\
21 \cdot 6^{+} \\
40 \cdot 1\end{array}$ & $\begin{array}{r}4 \cdot 6 \\
8 \cdot 3 \\
15 \cdot 6\end{array}$ & $\begin{array}{l}45 \\
52 \\
56\end{array}$ \\
\hline
\end{tabular}

AM, arithmetic mean; SL, short latency response; $M L$, medium latency response; $L L$, long latency response; $n$, number of measurable EMG responses; ${ }^{+}$, significant difference $(\mathrm{p}<0.05 \mathrm{t}$-test). 


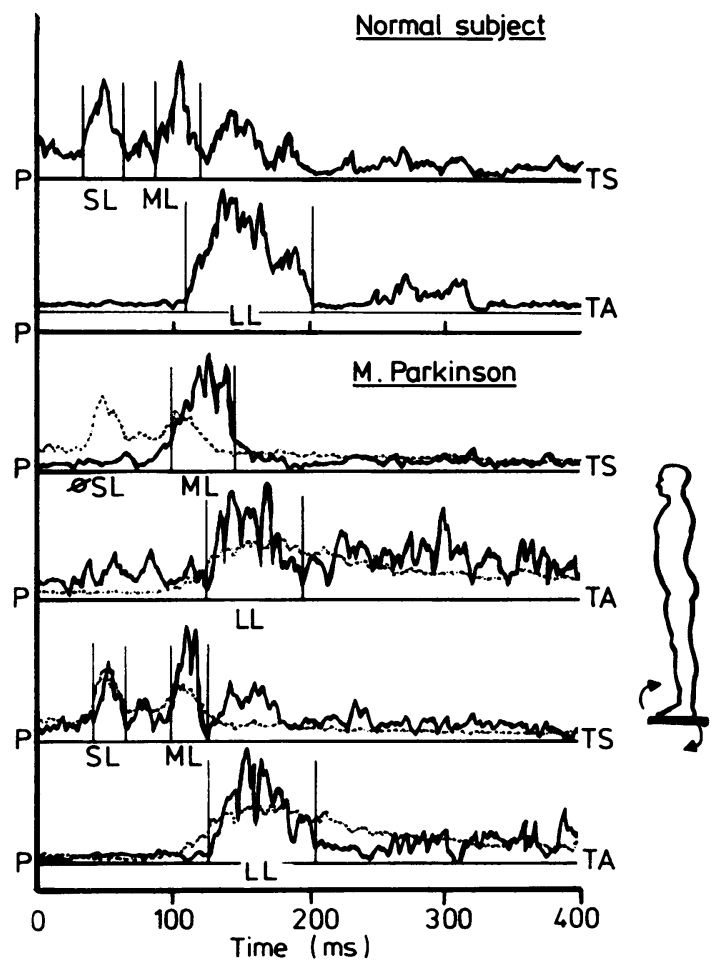

Fig 2 Short, medium, and long latency EMG responses of a normal subject (upper part) compared with EMGs from two patients with Parkinson's disease (lower part). Note the increased integral and duration of medium latency and the normal long latency response in the two patients (normalised $E M G$, maximum amplitude $=1)$. The dotted line indicates the grand average of the normal population, $P=$ preactivity.

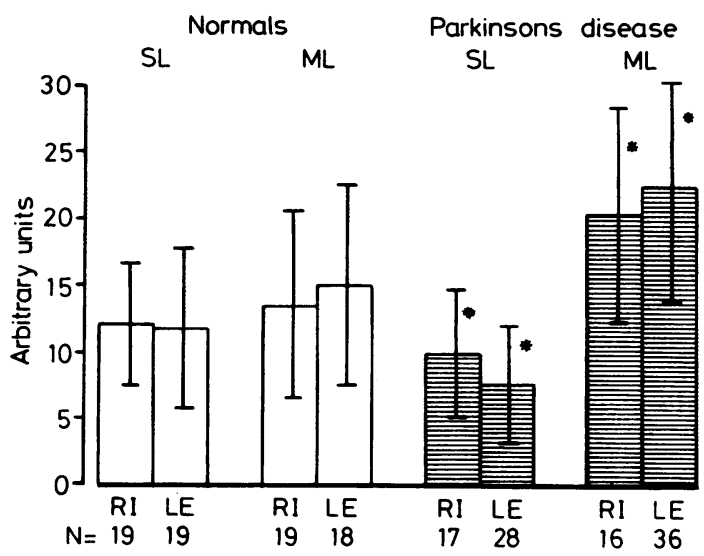

Fig 3 Means and standard deviations of the integrals of short latency and medium latency responses in triceps surae muscle for the right ( $R I)$ and left ( $L E)$ les in normals and patients with Parkinson's disease. Significant differences are indicated by stars $(p<0.05)$.
Scholz, Diener, Noth, Friedemann, Dichgans, Bacher

Quotient (SL-ML/SL+ML) M. triceps surae
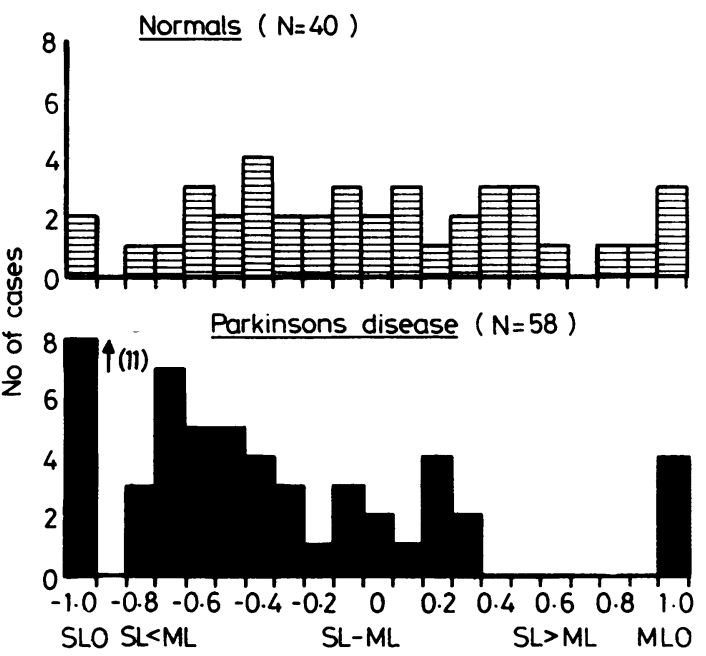

Fig 4 Distribution of the EMG quotient $Q=\frac{\int S L-\int M L}{\int S L+\int M L}$.

Missing short latency response, $Q=-1$, missing medium latency, $Q=+1$. In Parkinsonians $Q$ has its maximum at -0.7 indicating an increased medium latency response. Note that short latency response is missing in two normals and 11 patients, medium latency response is missing in three normals and four patients.

In the normal population the mean integral of the medium latency response was slightly greater than the integral of the short latency response (fig 3). Among patients with Parkinson's disease the average short latency integral was significantly decreased while the medium latency integral was augmented. In order to compare the integral of short latency and medium latency responses across normals and patients unrelated to the recording conditions we calculated the quotient

$$
Q=\frac{\int S L-\int M L}{\int S L+\int M L} .
$$

A medium latency integral exceeding short latency leads to a negative $Q(-0.1$ to -0.9$)$ (see fig 4$)$. The quotient was homogeneously distributed over the whole range from -0.9 to +0.9 among normals. In Parkinson's disease the quotient clearly shifted to negative values with a maximum at $-0 \cdot 7$, proving the increase of the medium latency integral. We were not able to find a correlation between the clinical score of rigidity and the calculated quotient of integrals. One patient with unilateral rigidity only showed a larger medium latency integral on the affected side, but not such a difference could be found in a second patient affected to a similar extent. 


\section{Discussion}

The results of our study confirm those of previous studies. ${ }^{1-5} 10$ showing that patients with Parkinson's disease exhibit a significant increase in amplitude (and duration) of the medium latency EMG response to muscle stretch in leg muscles. The latencies of medium latency and long latency EMG responses were normal in leg muscles. Only the short latency monosynaptic stretch reflex of triceps surae showed an increased latency. Patients with Parkinson's disease were clearly different from other patient groups such as Friedreich's disease or multiple sclerosis ${ }^{11}{ }^{12}$ in whom a delayed long latency response is recorded in the shortened antagonist. This delay is due to demyelination in the spinal and central afferent proprioceptive pathways.

New in this context is the fact that with our experimental paradigm in standing patients it is possible to separate clearly the medium from the long latency response in leg muscles. Owing to the inability to separate clearly the end of $\mathrm{M} 2$ from the beginning of M3 in wrist and finger muscles it was only possible to describe an increase of the M2/3 complex in Parkinson's disease. ${ }^{1}$ The quotient $\mathrm{Q}$ (see Results) indicated a relative increase of medium latency compared to the decreased short latency integral in triceps surae. The group of patients with Parkinson's disease showed a clear shift to negative quotients.

The physiological basis for rigidity is unsolved up to now. Lee and Tatton ${ }^{1}$ initially assumed that Parkinsonian rigidity could be caused by exaggerated M2/M3 responses via a transcortical feedback loop, the gain of which is constantly set at an increased level. If we apply this hypothesis to our results, it is the increased medium latency and not the normal long latency response which could contribute to the generation of rigidity. The variation of medium latency response amplitude in Parkinson's disease but unchanged latencies indicates a modulatory influence of supraspinal structures, such as the basal ganglia on this EMG response. The medium latency response according to our understanding and in accordance with Berardelli et $a l^{6}$ and Tatton et al ${ }^{13}$ could be a polysynaptic spinal reflex and perhaps has additional inputs from II-afferents. ${ }^{5}$ The long latency responses in hand muscles (M2/3) in contrast are most probably largely dependent on supraspinal pathways. ${ }^{1314}$

Corresponding to findings of Lee and Tatton, ${ }^{1}$ Tatton et $a l^{13}$ and Rothwell et $a l^{3}$ in arm muscles but in contrast to Berardelli $e a^{5}$ in triceps surae, the short latency response in the triceps surae muscle was decreased in amplitude in our patients, indicating that this spinal component could not contribute to rigidity in leg muscles. The base-line level of EMG activity preceding the disturbance was not increased in our patients (see fig 2) and, therefore, can be excluded as another possible cause of increased muscular tone. ${ }^{3}$ With regard to the individual patient we could not evaluate a clear correlation either between the enlarged integral of the medium latency response or the quotient $Q$ and the clinically assessed rigidity of the legs. This lack of a strong correlation was also observed by Rothwell et al, ${ }^{3}$ who found that the size of the long latency reflex was within the normal range in many patients with severe rigidity. One possible reason for the lack of correlation between rigidity and the integral of EMG responses is that rigidity is clinically assessed by slow passive movements of the leg and the wrist, whereas in our experiments fast muscle stretches were used.

One patient with on-off fluctuations, severe rigidity in the off-phase and hypotonia in hyperkinetic on-phases showed no significant change of both the short latency and medium latency integrals in both phases. Similar results have been reported by Dufresne et al. ${ }^{15}$

Further studies are necessary in order to show whether the recording of medium latency responses can provide an indicator for the possible success of medical therapy.

This work was supported by the Deutsche Forschungsgemeinschaft Di 278/1-2, ${ }^{1}$ SFB 200. ${ }^{2}$

\section{References}

1 Lee RG, Tatton WG. Motor responses to sudden limb displacements in primates with specific CNS lesions and in human patients with motor system disorders. Can J Neurol Sci 1975;2:285-93.

2 Lehmann-Horn F, Struppler A, Klein W, Lücking $\mathbf{C H}$, Burgmayer B, Deuschl G. Veränderungen der motorischen Kontrolle bei Parkinson-Patienten. In: Struppler A, ed. Elektrophysiologische Diagnostik in der Neurologie. Stuttgart: Thieme, 1982:236-7.

3 Rothwell JC, Obeso JA, Traub MM, Marsden CD. The behaviour of the long-latency stretch reflex in patients with Parkinson's disease. $J$ Neurol Neurosurg Psychiatry 1983;46:35-44.

4 Chan CWY, Kearney RE, Melvill-Jones G. Tibialis anterior response to sudden ankle displacements in normal and Parkinsonian subjects. Brain Res 1979;173:303-14.

5 Berardelli A, Sabra AF, Hallett M. Physiological mechanisms of rigidity in Parkinson's disease. $J$ Neurol Neurosurg Psychiatry 1983;46:45-53.

6 Berardelli A, Sabra AF, Hallett M, Berenberg W, Simon SR. Stretch reflexes of triceps surae in patients with upper motor neuron disease. J Neurol Neurosurg Psychiatry 1983;46:54-60.

7 Diener HC, Bootz F, Dichgans J, Bruzek W. Variability of postural "reflexes" in humans. Exp Brain Res 1983;103:423-8. 
8 Dichgans J, Diener HC. Flexibility of postural "reflexes" under different functional demands. In: Space Physiology. Centre National D'Etudes Spatiales, Cepaudes Editions 1983:97-104.

9 Hoehn MM, Yahr MD. Parkinsonism: onset, progression, and mortality. Neurology 1967;17:427-42.

10 Mortimer JA, Webster DD. Relationships between quantitative measures of rigidity and tremor and the electromyographic responses to load pertubations in unselected normal subjects and Parkinson patients. In: Desmedt JE, ed. Cerebral Motor Control in Man: Long Loop Mechanisms. Prog Clin Neurophysiol Vol 4. Basel: Karger, 1978:342-60.

11 Diener HC, Dichgans J, Bacher M, Guschelbauer B. Characteristic alterations of long-loop "reflexes" in patients with Friedreich's disease and late atrophy of the cerebellar anterior lobe. J Neurol Neurosurg
Psychiatry 1984;47:679-85.

12 Diener HC, Dichgans J, Hülser PJ, Buettner UW, Bacher M, Guschelbauer B. The significance of longloop responses for the diagnosis of multiple sclerosis. Electroencephalogr Clin Neurophysiol 1984;57:134-42.

13 Tatton WG, Bedingham W, Verrier MC, Blair RDG. Characteristic alterations in responses to imposed wrist displacements in Parkinsonian rigidity and dystonia musculorum deformans. Can $J$ Neurol Sci 1984;11:281-7.

14 Noth J, Podoll K, Friedemann HH. Long-loop reflexes in hand muscles studied in normal subjects and in patients with Huntington's disease. Brain 1985; 108:65-80.

15 Dufresne IR, Soechting IF, Tolosa ES. Myotatic reflexes and the on-off effect in patients with Parkinson's disease. J Neurol Neurosurg Psychiatry 1981;44:315-22. 